OPEN ACCESS

Edited by:

Branko Glisic,

Princeton University, United States

Reviewed by:

Lanata Francesca,

École Supérieure du Bois, France

Rostand Moutou Pitti,

Université Clermont Auvergne, France

*Correspondence:

Mariapaola Riggio

mariapaola.riggio@oregonstate.edu

Specialty section: This article was submitted to

Structural Sensing,

a section of the journal

Frontiers in Built Environment

Received: 19 May 2019

Accepted: 24 July 2019

Published: 09 August 2019

Citation:

Riggio M, Schmidt E and Mustapha G (2019) Moisture Monitoring Data of Mass Timber Elements During

Prolonged Construction Exposure:

The Case of the Forest Science Complex (Peavy Hall) at Oregon State University. Front. Built Environ. 5:98, doi: 10.3389/fbuil.2019.00098

\section{Moisture Monitoring Data of Mass Timber Elements During Prolonged Construction Exposure: The Case of the Forest Science Complex (Peavy Hall) at Oregon State University}

\author{
Mariapaola Riggio ${ }^{1 *}$, Evan Schmidt ${ }^{1}$ and Gamal Mustapha ${ }^{2}$ \\ ${ }^{1}$ Department of Wood Science and Engineering, Oregon State University, Corvallis, OR, United States, ${ }^{2}$ SMT Research, \\ Vancouver, BC, Canada
}

Keywords: mass timber buildings, on-site moisture performance, cross-laminated timber, hygrothermal monitoring, construction conditions

\section{INTRODUCTION}

Both the APA North American Standard for Performance Rated CLT (PRG 320) and the 2018 NDS specify dry service conditions $(<16 \% \mathrm{MC})$ for CLT, unless otherwise specified by the manufacturer (American Wood Council, 2018; ANSI/APA, 2018). The rate of moisture exchange between wood and the ambient environment due to diffusion is very slow and surface moisture contents rarely exceed $20 \%$ in covered outdoor conditions (Koch et al., 2016). Therefore, the concern lies primarily with direct exposure to bulk liquid, as it may happen in unprotected conditions during construction (Wang et al., 2018).

The lack of protocols for on-site protection of mass timber during construction is concerning, especially when considering the limited data currently available for hygrothermal performance analysis of CLT. In this regard, mass timber elements cannot be assumed as analogous to light-frame construction in terms of wetting and drying performance. These products have the capacity to store large volumes of water, and, due to the limits of bound water diffusion rates, exhibit much slower wetting, and drying behavior through their thicknesses (Wang, 2016). The potential for CLT to store moisture during construction exposure, and to retain that moisture for prolonged periods after enclosure within a building assembly, is thus a major concern.

Changes in the moisture content in the hygroscopic range (typically between 0 and $28 \%$ ) affect nearly every physical and mechanical property of the material, from strength and stiffness to thermal conductivity, and physical dimensions (Glass and Zelinka, 2010). Importantly, mechano-sorptive effects imply reduced stiffness and increased viscoelastic and plastic deformation with higher moisture contents during loading (Holzer et al., 1989; Pambou Nziengui et al., 2019). When applied at the global scale, these changes can impact building tolerances and serviceability. The effect of these phenomena on the performance of innovative timber systems, such as post-tensioned lateral load resisting system, is a research area still in development (Nguyen et al., 2019). Checking, interfacial shearing/delamination, and warpage observed on CLT exposed to environmental simulations within a laboratory (Schmidt et al., 2019) are examples of moisture-induced damage that can occur as a result of heavy environmental fluctuations, particularly when involving direct exposure to liquid water. 
This data report addresses these concerns and provides a unique set of hygrothermal data of mass timber elements exposed to fluctuating environmental conditions for almost 1 year during construction.

A large body of research exists in Europe on hygrothermal monitoring of glue laminated timber structures. These studies have tended primarily to focus on timber structures in covered outdoor conditions (service class 2 , according to ISO 21887) ${ }^{1}$. The moisture monitoring studies at Brock Commons in Vancouver, British Columbia (Mustapha et al., 2017, 2018), and at Carbon12 in Portland, Oregon (Zelinka et al., 2018), are among the few studies to date that have tracked the moisture content of CLT (and other timber components) exposed to rain throughout construction, and at a large scale (e.g., $>40$ MC locations). However, there is currently a lack of open-access monitoring data on moisture response of masstimber components, especially during prolonged exposure to environmental loading.

Peavy Hall is part of the Forest Science Complex at Oregon State University, Corvallis (OR). The building, under construction at the time of writing, showcases a wide range of mass timber products and construction systems, including cross-laminated (CLT) timber panels produced in Oregon. A hygrothermal monitoring plan was conducted during the construction of Peavy Hall with the aim to:

- Collect first-hand original data on some unique and innovative structural systems employing local materials, such as selfcentering rocking CLT shear walls;

- Develop benchmark data for further applications and crossreference with other projects.

Value and use of the data are listed below:

- Facilitate research advancement in the assessment of hygrothermal performance of mass timber products and the development of models (i.e., hygrothermal models, service life prediction models, etc.) that account for different factors (at the scale of the building, structural system and materials) affecting variability of moisture data.

- Educate mass timber industry and the AEC (architecture, engineering and construction) industry on the moisture behavior of CLT structural elements exposed to precipitations for a prolonged time during construction.

- Support development of refined moisture management practices of mass timber buildings.

- Support development of future hygrothermal monitoring projects of mass timber buildings.

- Provide a basis for development of models to reference sensor reliability.

This data report aims at guiding interested parties to the dataset and providing essential information for understanding the data.

${ }^{1}$ ISO 21887:2007. Durability of Wood and Wood-Based Products-Use Classes. ISO (the International Organization for Standardization) Geneva, C. H.

\section{METHODS}

The areas monitored during construction were in the zone scheduled as the first to be erected (Zone 1 in Figure 1). The CLT shear wall, with a N/S orientation, was erected on November 29th 2017 and outfitted with sensors 2 days later. The monitored floor connection is located on the first floor and comprised of a CLT floor panel and a glued-laminated beam. The monitored floor panel was installed on December 18th, 2017 and was outfitted with MC sensors on January 8th, 2018. The shear wall and the floor panel were made of seven and five lamellas (ply), respectively, of $5 \times 20 \mathrm{~cm}$ (nominal), PRG320 V1 grade (ANSI/APA, 2018) Douglas Fir (Pseudotsuga menziesii) lumber, bonded using melamine-formaldehyde (MF) resin (non-edge-glued).

A total of six and seven moisture sensors were installed at the upper and lower section of the shear wall, respectively. A total of six moisture sensors were installed at the floor connection (four in the floor panel and two in the beam). The monitoring period includes: (a) completion of the timber framing; (b) installation of the roof and façade water control membranes; (c) interruption of the construction work after finding manufactureoriginated delamination in some CLT panels; (d) resumption of the construction on August 2018; and (e) replacement of defective CLT panels (which included the monitored shear wall panel).

Monitoring locations were selected as representative areas at risk of moisture ingress and/or stagnation during construction. Considered factors for planning the monitoring locations included: construction schedule, duration of zone exposure, exposure to precipitation and wind-driven rain, aspect, orientation in space, detail complexity, presence of waterproofing elements, and weather sealants, presence of connectors and cuttings, potential for wicking from wood end grain panel ply depth.

Wood moisture content was measured using resistance sensors comprised of an electrode and a pair of insulated pins that record the ohmic resistance of wood at a specific depth. Different pin lengths were used to read wood moisture content at different depths in the member, approximately in the middle of the target ply (Figure 1c). The southernmost ply in the wall panel and the floor's lowest ply are both denoted "Ply 1" in the dataset.

For the installation of these sensors, the following procedure was followed: (a) selection of an area clear of macroscopic wood defects and devoid of discontinuities; (b) use of guides to keep constant pin spacing, (c) drilling of holes the exact length of the insulated housing using digital calipers, and drill-stops, (d) ramming in of the pins into the wood. A silicone bead was applied around the interface of the sensor with the shear wall panel, as well as around the exposed sensor head, to avoid condensation or moisture shorting due to direct water exposure, as well as to minimize heat conduction through the pins to the wood substrate on the south-exposed wall face.

Thermistors were embedded in the central area of the shear wall at different depths, at the center of plies 1, 4, 6, and 7, to monitor internal temperatures. Each one of these measured 

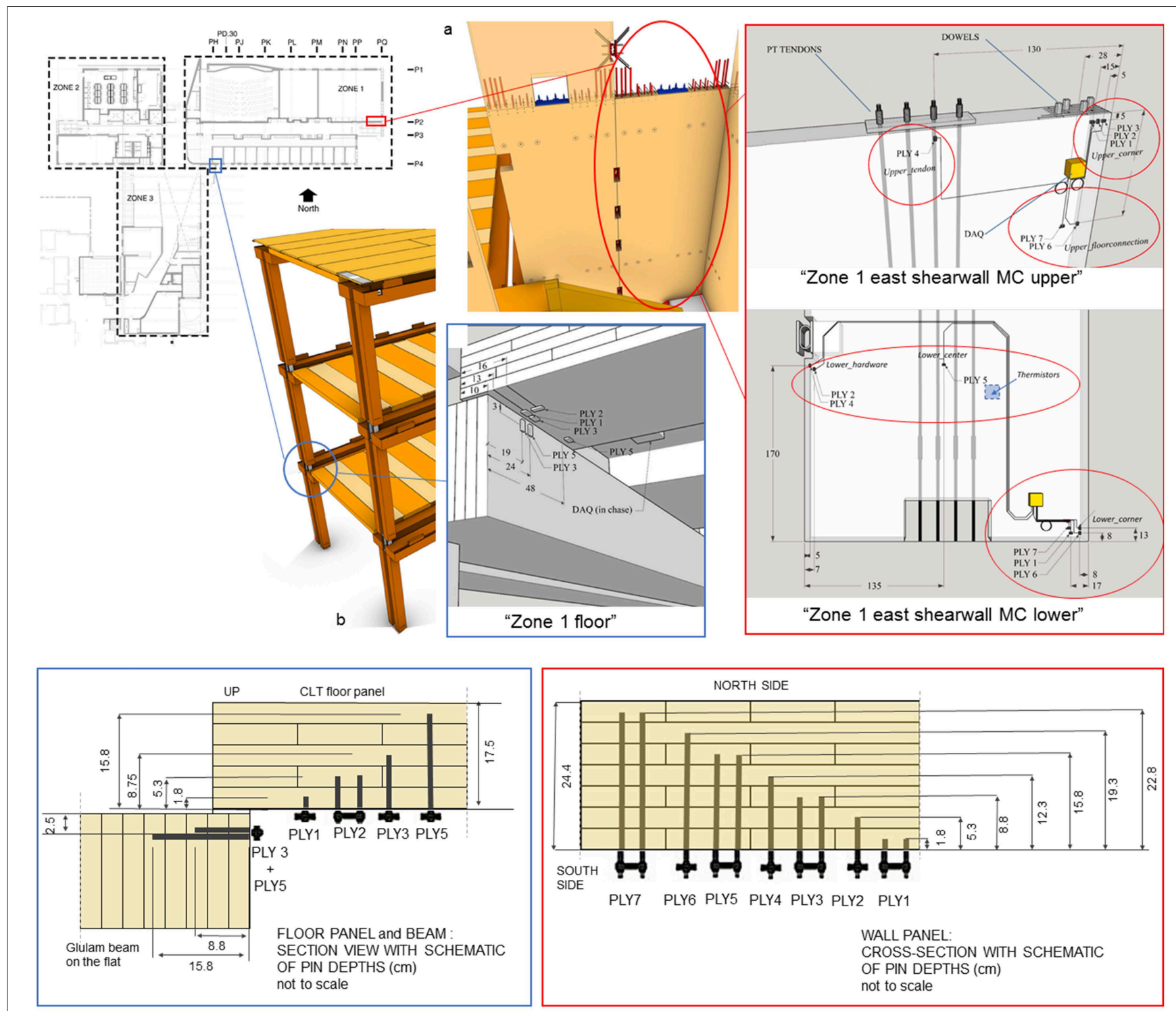

FIGURE 1 | Plan of Peavy Hall with location of monitored locations (a) shear wall; (b) floor; (c) schematic with pin depth of MC sensors.

depths was used as a representative datum for correcting MC measurements taken at the same depths, but at other locations in the same panel. The thermistors were inserted from the North side of the panel into boreholes that were subsequently sealed with silicone. Thermistors were installed on January 8th, 2018.

Moisture content data (resistance values) were calculated on an hourly basis. Data were periodically transmitted (by hardwire) to a data acquisition unit (DAQ) - a small weather-proofed box with eight resistance-type sensor channels-where they were stored and wirelessly transmitted to a dedicated computer with a receiver, and finally synced with a cloud data base. The Building Intelligence Gateway (BiG), served as the primary interface for the sensors.
Ohmic values read from the sensors are converted to $\mathrm{MC}$ values and then corrected using temperature data from the closest approximate thermistor depths. Conversion is performed through the BIG interface using the Garrahan formula (Equation 1) (Garrahan, 1988), which is based on the work of Pfaff and Garrahan (1986) extending the original work by James $(1963,1968)$. Their correction factors for species and temperature include a large number of wood species, in this case, published data for Douglas Fir were used. The manufacturer's calibration was not verified by comparison against oven-dry tests.

$$
M C=\left[\frac{R_{s}+\left(0.567-0.0260 x+0.000051 x^{2}\right)}{0.881\left(1.0056^{x}\right)}-b\right]+a
$$


A

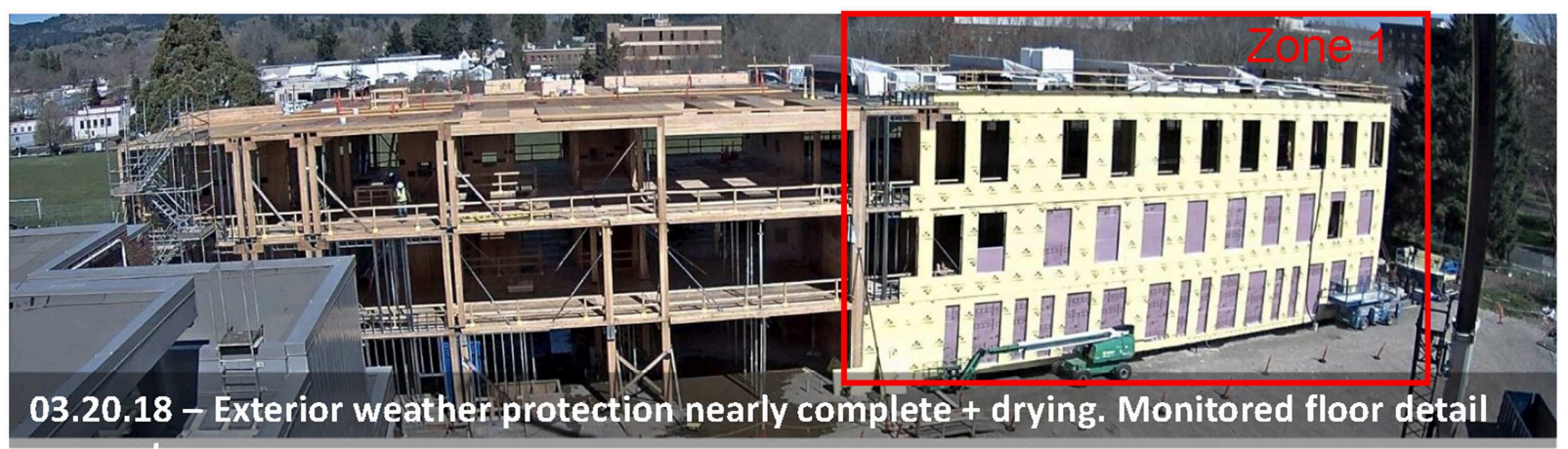

B

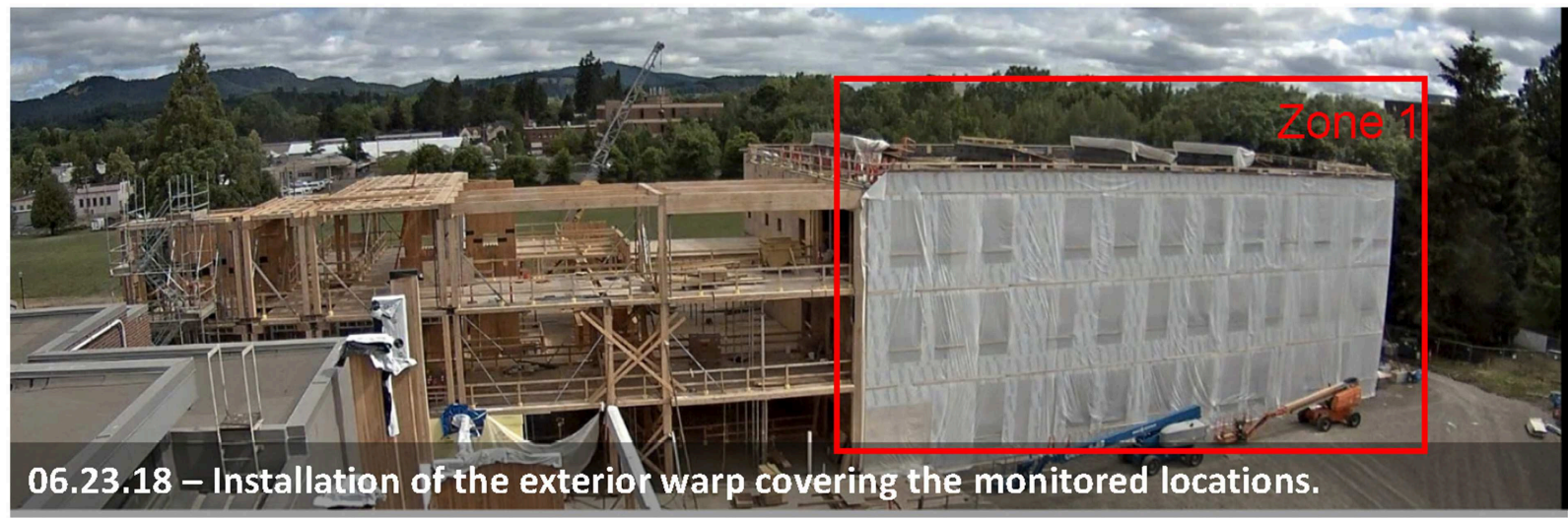

FIGURE 2 | Webcam images of the construction site.

Where:

$\mathrm{MC}=$ temperature and wood species corrected meter reading (wood moisture content)

$\mathrm{R}_{\mathrm{s}}=$ uncompensated moisture content $=$ $\mathrm{e}^{(4.095417-(0.14006 \times \ln (\mathrm{R})))}$

$\mathrm{R}=$ meter reading

$\mathrm{x}=$ wood temperature $\left({ }^{\circ} \mathrm{C}\right)$

$\mathrm{a}=0,838$

$\mathrm{b}=0,693$

Note that thermistor corrections weren't available to apply to the shear wall locations until January 6th, 2018.

Other data included in this report are weather (temperature, relative humidity, and precipitation) during the monitored period gathered from the Hyslop Weather Station ${ }^{2}$ close to the building location (Weather station coordinates: $44^{\circ} 38^{\prime} 03^{\prime \prime} / 123^{\circ}$ $11^{\prime} 24^{\prime \prime}$, Peavy Hall coordinates: $44^{\circ} 56^{\prime} 39^{\prime \prime} / 123^{\circ} 28^{\prime} 55^{\prime \prime}-$ Elevation: $230^{\prime}$ ).

\section{DESCRIPTION OF DATASET}

Hygrothermal monitoring data during construction of the Forest Science Complex at Oregon State University are permanently accessible from a publicly accessible

${ }^{2}$ Hyslop Weather Station Archives. Available online at: https://agsci.oregonstate. edu/corvallis-farm-unit/weather/weather-data (accessed July 3, 2019).
Open Science Framework repository: https:/osf.io/wymgt/ doi: 10.17605/OSF.IO/WYMGT.

The dataset contains data collected in four time frames:

December 1, 2017-November 21, 2018 (dataset name: Zone 1 east shearwall MC lower)

December 1, 2017-May, 17, 2018 (dataset name: Zone 1 east shearwall MC upper)

January 5, 2018-September 28, 2018 (dataset name: Zone 1 floor)

January 8, 2018-November, 22, 2018 (dataset name: Zone 1 Thermistors shearwall center)

December 1, 2017-November 22, 2018: (dataset name: OSU Weather Data (December 1 2017-November 22 2018).

This database is organized as a collection of CVS files. Moisture content and temperature data are named according to the location of the sensors and with data grouped according to each local data acquisition unit (DAQ).

Datasets include: (a) local wood MC data [\%]; (b) temperature data $\left[{ }^{\circ} \mathrm{C}\right]$ at different depths in the panel; (c) air temperature $\left[{ }^{\circ} \mathrm{C}\right]$; (d) $\mathrm{RH}$ data [\%] in the proximity of the DAQ, (e) weather data, consisting in $\left(e_{1}\right)$ latitude and longitude of the weather station; $\left(e_{2}\right)$ air humidity [\%]; $\left(e_{3}\right)$ air temperature low $\left[{ }^{\circ} \mathrm{F}\right] ;\left(\mathrm{e}_{4}\right)$ air temperature high $\left[{ }^{\circ} \mathrm{F}\right]$; $\left(\mathrm{e}_{5}\right)$ precipitation intensity $[\mathrm{in} / \mathrm{h}] ;\left(\mathrm{e}_{6}\right) \max$ precipitation intensity [in/h]. 


\section{ADDITIONAL REMARKS}

The experimental conditions in this study include some unplanned, uncontrolled factors, linked to the construction events. The following events are reported in this article:

On March 20th, 2018, the monitored floor detail was enclosed by a façade stud wall and water proof insulation, while a large window opening was left open in proximity of this detail (Figure 2A), resulting with water pooling at the connection during rain and subsequent limited drying conditions.

The same day a CLT panel at the third floor of Zone 1 failed as a consequence of manufacture-related defects (delamination). The construction was interrupted after the accident.

On June 23th, 2018, the entire Zone 1, including the monitored locations, was wrapped with waterproof sheets (Figure 2B) which were removed starting on July 23th, 2018.

Starting from September 18th and until November 28th 2018 all the installed sensors were progressively removed to allow replacement of the defective panels.

It is worth mentioning that:

1) Data of the first 6 months of construction, which are considered more representative of a typical construction schedule, are discussed in Schmidt and Riggio (Schmidt and Riggio, 2019).

2) Removal of the sensors from the monitored locations was not planned, but was due to the replacement of some CLT panels (including the monitored ones) affected by manufactureoriginated delamination.

3) There were no sensors installed in the panel that collapsed because of the above-mentioned delamination.

4) Installation of a total of 285 permanent sensors is in process in the building at the time of writing, and is not described in this Data Report. The new installation aims to collect in service data to analyze thermal insulation properties of CLT wall assemblies, long-term CLT floor creep, movement of the shear walls, post-tension loss of shear wall self-centering steel rods, global displacements due to ambient and seismic vibrations, and environmental conditions to correlate with the preceding phenomena (Baas et al., 2019).

\section{POTENTIAL USES}

Several tasks could be of interest to researchers using these data. Planning of sensor locations and definition of error

\section{REFERENCES}

America Wood Council (2018). National Design Specification (NDS) for Wood Construction 2018 Edition. Leesburg, VA: American Wood Council.

ANSI/APA (2018). PRG 320 Standard for Performance-Rated Cross-Laminated Timber. Tacoma, WA: American National Standard Institute/The Engineered Wood Association.

Baas, E. J., Riggio, M., Schmidt, E., Mugabo, I., and Barbosa, A. R. (2019). "Living lab at peavy hall: structural health monitoring of mass timber buildings," in 5th International Conference on Structural Health Assessment of Timber Structures (Guimarães). sources (e.g., due to temporarily sensor shortening) are some among the tasks that can be of interest to researchers in regard to these datasets. These datasets can be used to test and verify signal post-processing techniques. Data presented in Schmidt (Schmidt and Riggio, 2019) were manually postprocessed, including moving averages (Niklewski et al., 2017) and omission of readings, such as those outside the reliable moisture content reading range of the sensors. However, development of optimized, and automatic signal post-processing techniques is critical, especially if real-time monitoring moisture content data are made available to non-expert stakeholders. In addition, this data can be used to support development of models (i.e., hygrothermal models, service life prediction models, etc.) that account for different factors (at the scale of the building, structural system and materials) affecting variability of moisture data.

\section{DATA AVAILABILITY}

The datasets for this study can be found in the Open Science Framework repository: https://osf.io/ wymgt/; doi: 10.17605/OSF.IO/WYMGT.

\section{AUTHOR CONTRIBUTIONS}

MR served as principle investigator (funding acquisition, conceptualization of overarching research goals, design of methodology, supervision, and resource provision). MR and ES were both involved in experimental design, sensor installation, data acquisition/analysis, and writing. GM advised on the technical design of the experimental setup, and troubleshooting and also responsible for the implementation of the Building Intelligence Gateway $(\mathrm{BiG})$ that served as the primary interface with the sensors.

\section{FUNDING}

Funding for this study was provided by the U.S. Department of Agriculture Agricultural Research Service (USDA ARS) Agreement No. 58-0202-5-001 through the TallWood Design Institute at Oregon State University. This study was also funded by the McIntire Stennis project (contract number 1009740) provided by the National Institute of Food and Agriculture, U.S. Department of Agriculture. 
James, W. (1968). Effect of temperature on readings of electric moisture meters. For Prod. J. 18, 23-31.

James, W. L. (1963). Electric Moisture Meters for Wood. USDA-FS FPL-GTR-6. Madison, WI: U.S. Department of Agriculture, Forest Service, Forest Products Laboratory.

Koch, J., Simon, A., and Arndt, R. W. (2016). "Monitoring of moisture content of protected timber bridges," in Proceedings WCTE 2016 World Conference on Timber Engineering (Vienna).

Mustapha, G., Khondoker, K., and Higgins, J. (2017). "Moisture performance and vertical movement monitoring of pre-fabricated cross laminate timber featured case study : Ubc tallwood house," in 15th Canadian Conference on Building Science and Technology (Vancouver, BC), 1-15.

Mustapha, G., Khondoker, K., Higgins, J. (2018). "Structural performance monitoring technology and data visualization tools and techniques - Featured case study: UBC Tallwood House," in 1st International Conference on New Horizons in Green Civil Engineering (NHICE-01) (Vancouver, BC).

Nguyen, T. T., Dao, T. N., Aaleti, S., Hossain, K., and Fridley, K. J. (2019). Numerical model for creep behavior of axially loaded CLT panels. J. Struct. Eng. 145:04018224. doi: 10.1061/(ASCE)ST.1943-541X.00 02219

Niklewski, J., Isaksson, T., Frühwald Hansson, E., and Thelandersson, S. (2017). Moisture conditions of rain-exposed glue-laminated timber members: the effect of different detailing. Wood Mater. Sci. Eng. 272, 1-12. doi: 10.1080/17480272.2017.13 84758

Pambou Nziengui, C. F., Moutou Pitti, R., Gril, J., Fournely, E., Godi, G., and Ikogou, S. (2019). Notched-beam creep of Douglas fir and white fir in outdoor conditions: experimental study. Const. Mater. Build. 196, 659-671. doi: 10.1016/j.conbuildmat.2018.11.139

Pfaff, F., and Garrahan, P. (1986). New temperature correction factors for the portable resistance-type moisture meter. For Prod. J. 36, 28-30.
Schmidt, E., and Riggio, M. (2019). Monitoring moisture performance of crosslaminated timber building elements during construction. Buildings 9:144. doi: 10.3390/buildings9060144

Schmidt, E. L., Riggio, M., Barbosa, A. R., and Mugabo, I. (2019). Environmental response of a CLT floor panel: Lessons for moisture management and monitoring of mass timber buildings. Build Environ. 148, 609-622. doi: $10.1016 /$ j.buildenv.2018.11.038

Wang, J. (2016). "Wetting and drying performance of wood-based assemblies related to on-site moisture management," in Proceedings WCTE 2016 World Conference on Timber Engineering (Vienna), 1-22.

Wang, J. W., Stirling, R., Morris, P. I., Taylor, A., Lloyd, J., Kirker, G., et al. (2018). Durability of mass timber structures: a review of the biological risks. Wood Fiber Sci. 50, 110-27. doi: 10.22382/wfs-2018-045

Zelinka, S., Kordziel, S., Pei, S., and Glass, S. V. (2018). "Moisture monitoring throughout the construction and occupancy of mass timber buildings," in 1st International Conference on New Horizons in Green Civil Engineering (Vancouver, BC), 25-28.

Conflict of Interest Statement: GM was employed by the company SMT Research.

The remaining authors declare that the research was conducted in the absence of any commercial or financial relationships that could be construed as a potential conflict of interest.

Copyright (C) 2019 Riggio, Schmidt and Mustapha. This is an open-access article distributed under the terms of the Creative Commons Attribution License (CC BY). The use, distribution or reproduction in other forums is permitted, provided the original author(s) and the copyright owner(s) are credited and that the original publication in this journal is cited, in accordance with accepted academic practice. No use, distribution or reproduction is permitted which does not comply with these terms. 